\title{
EDITORIAL
}

\section{Can native plants become invasive?}

Plant species in nature are not always distributed evenly. There are dominant species as well as rare species while some show a wider distribution in ecosystems. It is also not unusual to find some extremely dominant species with a very high density and very rare species represented by only a few individuals. Rarity or dominance of a species in an ecosystem is determined by a multitude of extrinsic and intrinsic factors. Dominance of a species reduces the diversity of an ecosystem and its multifunctionality (Lohbeck et al., 2016). Rabinowitz (1981) proposed seven forms of rarity based on population size, geographic range and range of habitats. The most important extrinsic factor that causes species to become rare is perhaps the habitat destruction. Neighboring plants can also interfere by depleting limited resources such as light, water, nutrients, oxygen and carbon dioxide (Harper, 1977). Multitude of factors such as nonavailability of pollinators/dispersal agents, changes in climate and other edaphic factors could also be responsible for the changes of population size of a species. Species that become very rare may even become extinct if their density goes below a critical level needed to maintain a self-sustaining population.

As much as there are factors leading to rarity of plants, another set of factors may cause an exponential increase of individuals of a plant species in an ecosystem. This scenario can be considered as the other extreme of the same phenomenon which leads some plant species to extinct. The species that become extremely dominant compete with other co-occurring plants, depleting available resources ( Harper, 1977). Such species though it is an alien or a native show invasive traits. However, the term invasion is generally used in plant ecology for situations where the distribution and abundance of plants change as a result of human activities. Similarly, different terms such as "migration", "spread", "range expansion" or "range extension" are also been used (Pyšek and Richardson, 2008). Species that increase their population in their own habitat or else colonize on new habitats, in a geographical area where they are native can be termed as "expansive" while the process is known as the "expansion" (Pyšek and Richardson, 2008).

Invasiveness of a species is generally understood as the ability to spread and cause deleterious effects on organisms that exist in an ecosystem. The impacts of invasive species on biodiversity and functioning of ecosystems has been well documented and recognized as a primary cause for global biodiversity loss (Czech and Krausman, 1997) and species extinction (di Castri, 1989). These kind of adverse impacts on biodiversity are generally caused by alien invasive species. Even Charles S. Elton'sclassic book "The Ecology of Invasions by Animals and Plants" (Elton, 1958), which is considered as the origin of Invasion Biology, warns about the invasions of native ecosystems by non-native (alien) species.

The impact of Invasive Alien Species (IAS) on biodiversity has become a very important environmental issue during the last few decades and the cost of control has been a serious burden to many countries. United States of America alone spends over \$ 138 billion annually to control and manage IAS (Pimentel $e t$ al., 2005).There are several definitions to 
invasive species (Wijesundara, 2012). According to the Convention of Biological Diversity, IAS are defined as "species whose introduction and/or spread outside their natural habitats threaten biological diversity" (SCBD, 2009).

Are all invasive plant species alien? There are several instances where native species are considered as "invasive". For example, European species such as Pteridium aquilinum and Ulex europaeus are known to act as invasive in their native habitats. In Sri Lanka too, this kind of invasive behavior of several native bamboo species have been observed. Prematilleke et al. (2008) reported that Ochlandra stridula, a bamboo species endemic to Sri Lanka, is hindering the forest regeneration in the Meethirigala forest reserve.

If the factors responsible for controlling the population of a species suddenly become weak or absent, the density of that species may show an abnormal increase. Change of climate and/or other environmental factors may also cause an abnormal increase of species populations. For whatever reasons, those native species show aggressive characteristics similar to invasive species. However, since they are essential components of their resident ecosystem, it is not appropriate to identify them as 'invasive'. Instead, the word "expansive" (Pyšek and Richardson, 2008) or "super-dominant" can be used until a better term is coined.

\section{REFERENCES}

Czech, B. and Krausman, P.R. (1997). Distribution and causation of species endangerment in the United States. Science 277: 116-117.

Di Castri, F. (1989). History of biological invasions with special emphasis on the old world. John Wiley, Chichester, UK.

Elton, C. S. (1958). The ecology of invasions by animals and plants. London: Methuen, English Language Book Society.

Harper, J.L. (1977). Population Biology of Plants. Academic Press. 892 pp.

Lohbeck Madelon, Frans Bongers, Miguel MartinezRamos and Lourens Poorter (2016). The importance of biodiversity and dominance for multiple ecosystem functions in a humanmodified tropical landscape. Ecology 97 (10): 2772-2779.

Pimentel, D., Zuniga R. and Morrison, D. (2005). Update on the environmental and economic costs associated with alien-invasive species in the United States. Ecological Economics 52 (3): 273288.

Prematilleke, K., Madawala Weerasinghe, S. and Weerawardhana, N.D.R. (2014/2015). Biodiversity survey on Meethirigala Forest Reserve with special reference to the invasion of Ochlandra stridula. Sri Lanka Forester 36-37: 25-29.

Pyšek, P. and Richardson, D.M. (2008). Invasive plants. In:Jørgensen, S.E. (ed.), Encyclopedia of Ecology. Vol. 3. Elsevier, Amsterdam. 2011 pp.

Rabinowitz, Deborah (1981). Seven forms of rarity: The Biological Aspects of Rare Plant Conservation (Ed) Hugh Synge. John Wiley \& Sons Ltd. 205 pp.

SCBD (2009). Invasive Alien Species - A Threat to Biodiversity. Secretariat to the Convention on Biological Diversity. Montreal, Canada. 45 pp.

Wijesundara, S. (2010). Defining invasive alien species. In: Invasive Alien Species in Sri Lanka Strengthening Capacity to Control Their Introduction and Spread (Eds: Marambe, B., Silva, P., Wijesundara, S. and Atapattu, N.), pp 16. Biodiversity Secretariat of the Ministry of Environment, Sri Lanka

D.S.A. Wijesundara 